\title{
VII. On a new compound of chlorine and cyanogen
}

\section{James Stenhouse Esq.}

To cite this article: James Stenhouse Esq. (1841) VII. On a new compound of chlorine and cyanogen, Philosophical Magazine Series 3, 18:114, 29-32, DOI: 10.1080/14786444108650238

To link to this article: http://dx.doi.org/10.1080/14786444108650238

册 Published online: 01 Jun 2009.

Submit your article to this journal 준

Џ Article views: 2

Q View related articles $₫$ 


\begin{tabular}{|c|c|c|c|c|c|}
\hline No. & Direction of Prostration. & 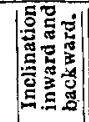 & No. & Direction of Prostration. & \\
\hline $\begin{array}{l}70 . \\
71 . \\
78 . \\
73 . \\
74 . \\
75 . \\
76 . \\
77 . \\
78 . \\
79 . \\
80 . \\
81 . \\
82 .\end{array}$ & 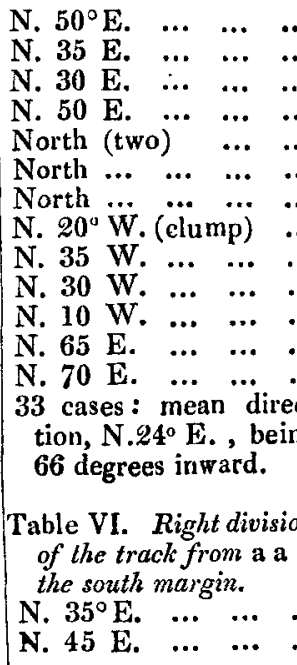 & \begin{tabular}{c|c}
.. & $40^{\circ}$ \\
.. & 55 \\
.. & 60 \\
.. & 40 \\
.. & 90 \\
.. & 90 \\
.. & 90 \\
.. & 110 \\
\hdashline. .125 \\
\hdashline .120 \\
$\ldots .$. & 100 \\
... & 25 \\
$\ldots .$. & 20 \\
$c-$ & \\
$n g$ &
\end{tabular} & $\begin{array}{l}84 . \\
85 . \\
86 . \\
87 . \\
88 . \\
89 . \\
90 . \\
91 . \\
92 . \\
93 . \\
94 . \\
95 .\end{array}$ & 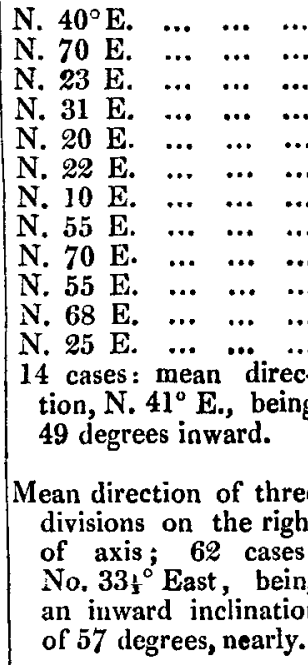 & \begin{tabular}{c|c}
.. & 5 \\
.. & 2 \\
.. & 6 \\
.. & $5 !$ \\
.. & 7 \\
.. & 6 \\
.. & 8 \\
.. & 3 \\
.. & 2 \\
.. & 3 \\
.. & 2 \\
.. & 6 \\
$c-$ & \\
g & \\
ee \\
ht \\
s: \\
ng \\
on \\
.
\end{tabular} \\
\hline
\end{tabular}

VII. On a new Compound of Chlorine and Cyanogen. By James Stenhouse, Esq.*

THIS somewhat remarkable compound may be obtained by two processes, both of which I shall now minutely describe. The first way in which I obtained it was by decomposing an alcoholic solution of bicyanuret of mercury by dry chlorine gas. The method of proceeding is the following. Four or five ounces of bicyanuret of mercury should be finely powdered, and introduced into a tubulated retort, and the same weight of strong alcohol poured over them. It is proper to agitate the mixture for some time, and even to heat it a little, in order to saturate the alcohol completely with the salt. The retort is then to be kept as cool as possible by being placed in a vessel of cold water, a copious stream of which is to be kept falling upon it during the whole process. The chlorine to be introduced into the solution of the bicyanuret of mercury must be dried, by being passed through an intermediate vessel containing sulphuric acid: it may then be conveniently introduced into the solution by a tube passed

* Communicated by the Author; having appeared in Liebig's Annalen for January, 1840, 
through the tubulure of the retort, and reaching nearly to its bottom. The current of chlorine is to be sent through the liquid very slowly : if this is not attended to, the temperature rises very high, and the gaseous chloride of cyanogen passes off as fast as it is formed, instead of being absorbed by the alcohol, and the quantity of the compound obtained is exceedingly diminished, if indeed its formation be not wholly prevented. When this is the case heavy muriatic æther is almost the only product; but by careful cooling and cautious evolution of the chlorine this result may be easily prevented.

When the current of chlorine has been sent through for some time, abundance of crystals begin to appear in the retort, accompanied by a violent effervescence. These crystals will be found to be sal-ammoniac, the quantity of which, when there was not much alcohol in the retort, is so great as to convert the whole into a solid mass. If the chlorine is continued to be sent through the liquid after the crystals of salammoniac have appeared, it forms abundance of the heavy muriatic æther, which adheres tenaciously to the chlorocyanous compound, and from which it can be separated only by repeatedly dissolving it in hot alcohol, and precipitating it by water. If any trace of this æther remains adhering to the crystals, it communicates to them its peculiar smell and greasy feel, and lowers their melting point very considerably.

If the alcoholic solution is then treated with water, the sal-ammoniac is dissolved, and the cyanogen compound falls in great abundance in long silver-white needles. If this is done by hot water the crystals form more slowly, and become therefore larger and more beautiful. When the liquid has stood some time the crystals are to be collected and washed upon a filter with cold distilled water, till every trace of acid is removed; they are then quite pure. The salt which remains in solution after the crystallization of the cyanogen compound is not corrosive sublimate, as might be expected; it is the combination of chloride of mercury and sal-ammoniac usually known as the sal-d'Alembroth; it is much more soluble than corrosive sublimate.

I shall now describe the second method, which is much more œconomical.

Strong hydrocyanic acid is first made in the usual way by sulphuric acid and prussiate of potash. It is then to be redistilled, and to be condensed in the alcohol intended to be used, until the latter is saturated with the acid. The other arrangements are precisely the same as in the first process; and the too rapid evolution of chlorine, or the heating of the solution, must be carefully guarded against. The chlorine is 
continued to be sent through the liquid till the crystals of salammoniac begin to form, which is accompanied by the violent effervescence I have before mentioned, owing to the escape of carbonic acid gas.

The cause of these phænomena is owing to the decomposition of chloride of cyanogen, by its constituents uniting with the elements of four equivalents of water, and giving rise to sal-ammoniac and carbonic acid, as will be readily seen from the following symbols.

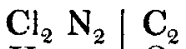

$$
\begin{aligned}
& \mathrm{H}_{8} \quad \mathrm{O}_{4} \\
& \text { or } \mathrm{C}_{2} \mathrm{~N}_{2} \mathrm{Cl}_{2}+\mathrm{H}_{8} \mathrm{O}_{4}=\mathrm{C}_{2} \mathrm{O}_{4}+\mathrm{N}_{2} \mathrm{H}_{8} \mathrm{Cl}_{2} \text {. } \\
& \text { Properties of the Compound. }
\end{aligned}
$$

The compound crystallizes in long, soft, perfectly white needles, of a silvery lustre; they very much resemble sulphate of quinine: it is neutral to test paper; it is tasteless and inodorous; it melts at $140^{\circ} \mathrm{C}$, by which heat it is partly sublimed. When heated to $160^{\circ} \mathrm{C}$. it is decomposed, and emits a smell resembling that of benzoic æther. It burns easily with a large yellow flame, resembling that of alcohol, and emits no smoke. It is little soluble in cold water, but so much so in boiling as to be deposited in crystals on the cooling of the liquid. In alcohol and æther it is very soluble, but it may be precipitated from either solvent by water : it is deposited in crystals on their evaporation.

When heated with an aqueous solution of potash it is decomposed with the evolution of ammonia, and the solution becomes of a deep brown colour. With a solution of liquid ammonia in the cold there is no action, but it is dissolved on the application of heat, and is deposited unaltered on the cooling of the liquid. Sulphuric acid dissolves it very readily when assisted by a gentle heat; it is not in the least blackened; it does not precipitate on the cooling of the liquid, but water causes the precipitation of it in an apparently unaltered state.

The analyses conducted in the usual way gave the following results.

1st. 0.7902 of the combination gave 1.022 carbonic acid and 0.360 water.

2nd. 0.505 gave 0.658 carbonic acid and 0.227 water.

1st. 0.7925 gave by decomposition at red heat by quick lime 0.833 chloride of silver, equal to 25.930 per cent.chlorine.

2nd, 0.5245 gave 0.555 chloride of silver equal to 26.10 per cent. chlorine.

The nitrogen was determined qualitatively. The carbonic 
acid was to the nitrogen in the proportion of $8:: 1$ by volume, accordingly $8:: 2$ in atomic proportion.

This gives the following result.

1.

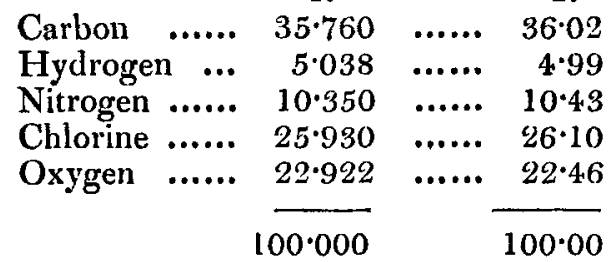

Theoretical composition.

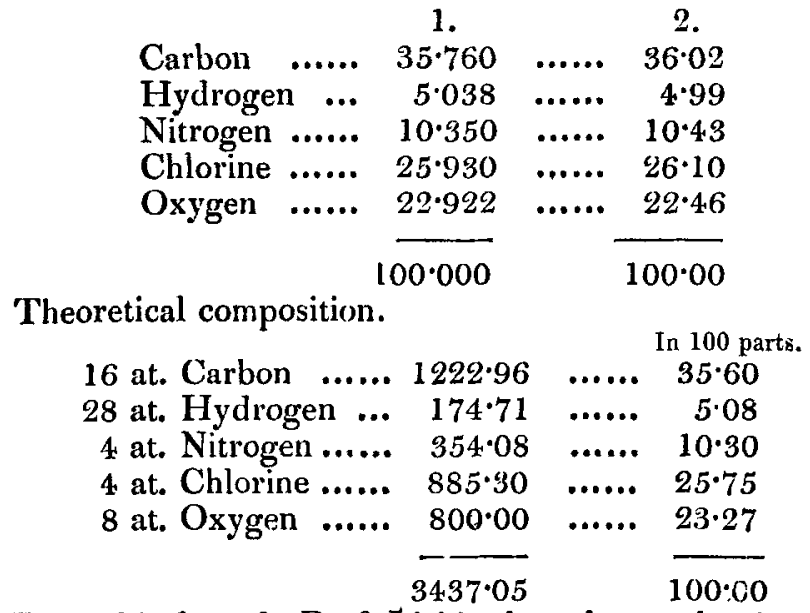

From this formula Prof. Liebig has shown that it may be considered as a combination of 3 atoms aldehyd, 2 atoms chlorcyan, and 5 atoms of water, as follows.

$$
\begin{aligned}
& 3 \text { at. Aldehyde } \\
& =\mathrm{C}_{12} \mathrm{H}_{18} \mathrm{O}_{3} \\
& 2 \text { at. Chloride of cyanogen }=\mathrm{C}_{4} \\
& 5 \text { at. Water } \\
& =\frac{\mathrm{H}_{10} \mathrm{O}_{5} \mathrm{~N}_{4} \mathrm{Cl}_{4}}{\mathrm{C}_{16} \mathrm{H}_{28} \mathrm{O}_{8} \mathrm{~N}_{4} \mathrm{Cl}_{4}}
\end{aligned}
$$

VIII. On the Composition of Chelidonin and Jervin. By Dr. HEINRICH WILL *

THE organic bases employed in the following analyses were prepared and sent to me to be analysed by their discoverers; the chelidonin by Dr. Probst of Heidelberg, and the jervin by E. Simon, apothecary in Berlin.

Chelidonin.+- The chelidonin, whose properties and mode of preparation have been described by Probst, forms a pure white, soft powder, and is also obtained in a crystalline form. When heated it melts into a colourless oily fluid, which becomes brown at a stronger heat; finally it takes fire and burns away with a bright smoky flame, without leaving the least residue. The base dried in the air contains water of crystallization which disappears completely at a temperature of 100

* From Liebig's Amalen der Pharmacie for July, 1840: vol. xxxvpart 1 .

t See the Supplementary Number for the present month, vol, xvii. p.543. 